ISSN 1916-7822. A Journal of Spread Corporation

Volume 10. No. 22021 Pages 37-52

\title{
Emotional Intelligence, Social Networking Skills and Online Counselling Communication Effectiveness Among Students of OAU, Ile-Ife, Nigeria
}

\author{
Eli Segbeyon Gabriel, Olusegun Fatai Adebowale, \\ Oluwaseun Solomon Omotehinse \\ Dept of Educational Foundations and Counselling \\ Faculty of Education, Obafemi Awolowo University, Ile-Ife, Nigeria
}

\begin{abstract}
With a view to providing empirical information on the factors that influence online counselling communication among Nigerian university students, this study investigated the influence of emotional intelligence and social networking skills on the effectiveness of online counselling communication among students of Obafemi Awolowo University (OAU). Through a descriptive survey research design, the study sampled 100 students purposively from users of the University online counselling platform, on the basis of being able to have established complete counselling interaction with any of the counsellors online during the harmattan and rain semesters of 2017/2018 session (or over a period of 12 months.). The results showed that $78.0 \%, 19.0 \%$ and $3.0 \%$ of the students demonstrated high, moderate and low levels of online counselling communication effectiveness respectively and that emotional intelligence has significant influence on online communication effectiveness $(\beta=0.790, p<0.05)$. The results further showed that social networking skills has no significant influence on online communication effectiveness $(F=3.457$, $p>0.05)$ and no significant interaction effect of emotional intelligence and social networking skill was found on online counselling communication effectiveness $(F=0.546, p>0.05)$. The study concluded that the only factor that influenced online counselling communication effectiveness among the students under study is emotional intelligence.
\end{abstract}

Keywords: Communication Effectiveness, Social Networking, Emotional Intelligence

\section{Introduction}

The major activity involved in counselling interaction is communication. The clients communicate their concerns involving emotional troubles, fears, anxiety, prospect, and worries to the counsellor, while the counsellor communicates in return their competencies, counselling skills, and guidance material to the client. This is done generally using verbal and/or non-verbal communication. 
Counsellors take into cognisance the verbal expressions of clients while reporting their experiences, dreams, frustrations, anxieties, and even their state of mind. Of critical importance is the careful attention given to client's non-verbal communication in a counselling encounter.

Communication is a process comprising of elements, the sender, encoding the message, transmitting the message through a medium, receiving the message, decoding the message, feedback, and noise. These elements in the communication process determine the quality of communication. Keyton (2011) argued that a problem in anyone of these elements can reduce communication effectiveness. Communication becomes effective when the receiver obtains the message and provide (an) indication that the message has been received and understood as intended by the sender. Effective communication, therefore, is an essential component of relational success at the interpersonal, intergroup, intragroup, or organizational levels. Any hitch to or conflict with any of these elements can reduce communication effectiveness (Keyton, 2011). For example, information must be encoded into a message that can be understood as the sender intended through a particular medium that must be carefully selected for effective communication.

Conditions required for communication effectiveness in face-to-face encounter has been roundly debated and largely agreed upon. For instance, several communication theorists (Cheney, 2011; Keyton, 2011; Tourish, 2010) have gleaned elements of good communication, which are particularly applicable to both the sender and the receiver. These elements, together with a basic understanding of the communication process itself, should provide a good foundation for developing and maintaining effective communication skills, which counsellors can use when communicating in a face-to-face encounter.

However, given the limitations commonly expressed for online communication especially for online counselling in which communication effectiveness is of paramount importance, exploring factors which will promote communication effectiveness becomes germane. Online counsellors need to be sure that the information provided the client across the internet or any other online media is received and understood as intended in order to determine the type of feedback that will be effective in the counselling relationship, the next line of action in the counselling process, referral provisions and the effectiveness of the counselling relationship itself. It is also expected that the increasing acceptance of online counselling require that effective communication on this mode of counselling be explored.

However, despite the increasing acceptance of online counselling amongst service users, factors that could help to improve communication on it have received very little or no attention. 
For instance, from search in literature, it was not shown where personal factors like Emotional Intelligence (EI) and Social Networking Skill (SNS) have been studied in connection with effectiveness of online counselling communication.

For much of the previous centuries, emotion scholars generally subscribed to cultural theory of emotion in which emotion were believed to be culturally specific learned behaviours that could only be experienced by observing other people expressing such emotions (Creed \& Beale, 2006). This includes the ability to accurately perceive and express emotion, identify emotion in the self and others, assimilate emotion into thought, and use information that explains felt emotions in order to prioritize and direct thinking. These factors of EI are said to influence the effectiveness of communication between sender and receiver. Scientists and psychologists of emotional intelligence theory argue that emotional intelligence may also lead to improved communication skill (Hazard, 2000). Goleman (2002) suggested that to be emotionally and socially intelligent is to effectively understand and express oneself, to understand and relate well with others and successfully cope with daily demands, challenges and pressures. Individuals with better emotional intelligence can better perceive emotions, use them in thought, understand the meaning of thought, encode it in proper message and can manage their emotions well. There is thus a need to study emotional intelligence in relation to communication to enhance its effectiveness.

One of the first steps to sending a message is encoding it, that is, the process of converting information into another acceptable form, for transmission. Decoding reverses this process in order to interpret the information. Encoding is done using words, symbols, pictures, symbols and sounds. When encoding a message, the sender begins by deciding what he/she wants to transmit. It is important for the sender to use symbols that are familiar to the intended receiver. A good way for the sender to improve encoding of their message is to mentally visualize the communication from the receiver's point of view. The encoded message must now be delivered to its audience via a message channel. A message channel is a term that refers to the medium that carries the message from the sender to the receiver.

It therefore follows that when a message is not properly coded, even if it is received and it generates an understanding, there will be chances that the understanding generated will be in variance with what the sender intends. In computer mediated communication, social networking skills are considered germane to communication effectiveness as this represent the skills of encoding message to receivers which are commonly friends, online acquaintances and other 
contacts. Some of these social networking skills include use of emoticons, computer literacy, typing ability and speed, online text-chatting skills and so on.

Since social networking is increasingly popular amongst people regardless of geographical location, background and age, developing social networking skills is very vital. These skills help in forming strong and formidable relationships on different online social media platforms. Thus, there is a compelling need to explore the link between social networking skills and communication effectiveness in online counselling.

\section{Objective of the Study}

The main objective of this study is to investigate the influence of emotional intelligence and social networking skills on the effectiveness of online counselling communication among students of Obafemi Awolowo University (OAU), Ile-Ife. The specific objectives are to:

1. determine the level of online counselling communication effectiveness among the students of Obafemi Awolowo University, Ile-Ife.

2. investigate the influence of the students' emotional intelligence on the effectiveness of online counselling communication.

3. examine the influence of student's social networking skills on the effectiveness of online counselling communication.

4. investigate interaction effect of emotional intelligence and social networking skill on communication effectiveness of online counselling communication.

\section{Research Questions}

1. What is the level of online counselling communication effectiveness among the students of Obafemi Awolowo University, Ile-Ife?

2. What is the influence of the student-client's emotional intelligence on the effectiveness of online counselling communication?

3. What is the influence of student-client's social networking skills on the effectiveness of online counselling communication?

4. What interaction effect does emotional intelligence and social networking skill have on communication effectiveness of online counselling communication?

\section{Methodology}

The study adopted the descriptive survey research design. The population consisted of all undergraduate and postgraduate students of Obafemi Awolowo University. The OAU online 
counselling platform is synchronous, where counsellors and clients can have instantaneous interactions. However, clients can leave offline messages for counsellors in case they are not online when they visit. The online counselling platform was designed in such a way that students/clients who visit can engage with counsellors using pseudo identities that could not be traced to them. Interactions with student-clients are recorded under these pseudonyms that are given by the client and subsequent or follow-up visits to the online counselling platform are based on them. Information given by a client is only accessible to the online counsellor and such client. Copies of online questionnaire were sent to the users of the platform out of which 100 copies were selected for analysis. The selection was based on only those who had successful counselling relationships with the online counsellors with full and complete counselling sessions/interactions until their issues of concern were completely resolved.

The questionnaire contained 4 Sections. Section A contained information on participants' demographic variables, including gender, Age range; faculty of affiliation; undergraduate. Section B, below, contained items on social networking skills developed by Author (2013).

\begin{tabular}{|l|l|l|l|l|l|l|}
\hline S/N & Online Social Networking Skills & None & Novice & Fair & Good & Expert \\
\hline 1. & Computer literacy & & & & & \\
\hline 2. & Typing speed & & & & & \\
\hline 3. & Online text-chatting skills & & & & & \\
\hline 4. & Creativity in self-expression through writing. & & & & & \\
\hline 5. & $\begin{array}{l}\text { Ability to use audio/video teleconferencing } \\
\text { facilities. }\end{array}$ & & & & & \\
\hline 6. & $\begin{array}{l}\text { Using emoticons (seen a helpful nonverbal } \\
\text { indicators). }\end{array}$ & & & & & \\
\hline 7. & $\begin{array}{l}\text { Time effectiveness (fulfilling online appointments } \\
\text { and durations) }\end{array}$ & & & & & \\
\hline 8. & Finding a website I visited before & & & & & \\
\hline 9. & $\begin{array}{l}\text { Ability to change who I share online content with } \\
\text { (e.g. friends, friends of friends). }\end{array}$ & & & & & \\
\hline 10. & Ability to download files. & & & & & \\
\hline 11. & Ability to open new tab in my browser. & & & & & \\
\hline 12. & Ability to bookmark a website. & & & & \\
\hline 13. & Ability to click and go to a different webpage & & & & & \\
\hline 14. & Ability to complete online forms. & & & & \\
\hline 15. & Ability to connect to a Wi-Fi network information. & & & & \\
\hline
\end{tabular}


Section C, below, is a scale on respondents' Communication Effectiveness developed by Francis (2016) designed to measure the communication effectiveness of counsellors and clients in online counselling relationships The participants choices of response were $A=A l w a y s, S=S o m e t i m e s$, $\mathrm{R}=$ Rarely and $\mathrm{N}=\mathrm{Never}$.

\begin{tabular}{|c|c|c|c|c|c|}
\hline $\mathrm{S} / \mathrm{N}$ & ITEMS & A & $\mathrm{S}$ & $\mathrm{R}$ & $\mathrm{N}$ \\
\hline 1. & My online counsellor's statements are clearly constructed and easily understandable & & & & \\
\hline 2. & $\begin{array}{l}\text { I believe the words I choose in communication with the online counsellor will convey } \\
\text { most of my message }\end{array}$ & & & & \\
\hline 3. & $\begin{array}{l}\text { Once I read the statement sent to me by the online counsellor, I can predict what } \\
\text { his/her conclusion will be. }\end{array}$ & & & & \\
\hline 4. & $\begin{array}{l}\text { When I'm not sure about what s/he is saying to me, rather than ask questions, I'll } \\
\text { wait to learn more. }\end{array}$ & & & & \\
\hline 5. & $\begin{array}{l}\text { When my counsellor asks, "do you understand," I say "yes" even if I'm not entirely } \\
\text { sure. }\end{array}$ & & & & \\
\hline 6. & $\begin{array}{l}\text { I believe effective communication can be achieved in online counselling simply by } \\
\text { taking turns to exchange messages }\end{array}$ & & & & \\
\hline 7. & My counsellor uses open questions to find out facts & & & & \\
\hline 8. & $\begin{array}{l}\text { The counsellor makes use of appropriate net lingo (emoticons, abbreviations and } \\
\text { symbols) }\end{array}$ & & & & \\
\hline 9. & The counsellor helps to summarize my thoughts to ensure understanding & & & & \\
\hline 10 . & $\begin{array}{l}\text { The counsellor uses easily understood everyday words and expressions that everyone } \\
\text { is familiar with }\end{array}$ & & & & \\
\hline 11. & I can imagine the counsellors' non-verbal communication during online chats & & & & \\
\hline 12 & S/he avoids the use of jargons and technical languages. & & & & \\
\hline 13. & S/he knows when to use a coded questions to get 'yes/no' answers. & & & & \\
\hline 14. & $\begin{array}{l}\text { S/he structures their thought in a logical and rational way to help others to understand } \\
\text { their world. }\end{array}$ & & & & \\
\hline 15. & The counsellor keeps our communication confidential & & & & \\
\hline
\end{tabular}

Section D on the questionnaire below was developed by Davies (2008) and was designed to measure the emotional intelligence of counsellors and clients in online counselling relationships. Participants' choice of answers were A=Always, $\mathrm{S}=$ Sometimes, $\mathrm{R}=\mathrm{R}$ arely and $\mathrm{N}=\mathrm{Never}$.

\begin{tabular}{|c|c|c|c|c|c|}
\hline $\mathrm{S} / \mathrm{N}$ & ITEMS & A & $\mathrm{S}$ & $\mathrm{R}$ & $\mathrm{N}$ \\
\hline 1. & $\begin{array}{l}\text { In online counselling relationships, I always know which emotions I am feeling and } \\
\text { why }\end{array}$ & & & & \\
\hline 2. & $\begin{array}{l}\text { Through online counselling relationships, I am able to realize the links between my } \\
\text { feelings and what I think, do, and say }\end{array}$ & & & & \\
\hline 3. & Through counselling, I recognize how my feelings affect my performance & & & & \\
\hline
\end{tabular}


Emotional Intelligence, Social Networking Skills and Online Counselling Communication Effectiveness Among Students of OAU, Ile-Ife, Nigeria

\begin{tabular}{|l|l|l|l|l|}
\hline \hline 4. & Through counselling relationship, I have a guiding awareness of my values and goals & & & \\
\hline 5. & $\begin{array}{l}\text { I am open to candid feedback, new perspectives, continuous } \\
\text { learning, and self-development }\end{array}$ & & & \\
\hline 6. & $\begin{array}{l}\text { During online counselling session, I am able to show a sense of humour and } \\
\text { perspective about myself }\end{array}$ & & & \\
\hline 7. & During counselling, I manage my impulsive feelings and distressing emotions well & & & \\
\hline 8. & I think clearly and stay focused during counselling relationships & & & \\
\hline 9. & I meet commitments and keep promises with my online counsellor & & & \\
\hline 10. & I hold myself accountable for meeting my counselling objectives & & & \\
\hline 11. & I take fresh perspectives and risks in my thinking through counselling & & & \\
\hline 12. & I continuously learn from my counsellor in order to improve my performance & & & \\
\hline 13. & I am willing to make personal sacrifices to meet my counselling goals & & & \\
\hline
\end{tabular}

Data collection was done by preparing the questionnaire as Google Forms with the link sent to participants through the online counselling platform. Respondents' questionnaires were automatically returned when they clicked a submit button when their responses were registered in the database of the researchers' mailbox from where they were transcribed on to the Excel data format and then converted to SPSS for analysis. The data were analysed using frequency counts, percentage, and linear and two-way ANOVA.

\section{Results}

Research Question \#1: What is the level of Online counselling communication effectiveness among students of Obafemi Awolowo University, Ile-Ife?

To answer this research question, the responses provided by the research participants were scored in such a way that when a respondent chose an "always" option in the section C of the online questionnaire, $\mathrm{s} /$ he is allotted a score of 4 and when a "sometimes" option, a score of 3 was allotted. Also, when a "rarely" option was chosen a score of 2 was allotted and when the respondent chose a "Never" option, s/he was allotted a score of 1 . The resulting scores were aggregated and was made to constitute a measure of communication effectiveness indicated by each of the respondents. On the measure, the maximum value obtained was 58 while the minimum value was 17 . Also, the mean score was 48.13 with a standard deviation of 6 . However, the values were categorized in line with the original version of the scale (Francis, 2016) in which a score of 30 or less on the measure was said to be of low level of communication effectiveness while a score of 31 to 45 was said to be moderate level and any score in excess of 46 was said to be of high level of communication 
effectiveness. These categories were summarized descriptively, and the result is presented in Table 1

Table 1: Level of Online counselling communication effectiveness among OAU students

Level of communication $\quad$ Frequency Percent
effectiveness

Low

3

3.0

Moderate

19

19.0

High

78

78.0

Total

100

100.0

Table 1 presents the summary of the level of online counselling communication effectiveness among OAU students. The table also shows that most of the respondents (78\%) experienced a high level of communication effectiveness during their online interaction with their counsellors while $19 \%$ experienced moderate level. Only a very small percentage (3\%) indicated that they experienced a low level of online counselling communication effectiveness.

Research Question \#2: What is the influence of the student-client emotional intelligence on the effectiveness of online counselling communication?

To answer this research question, the student-clients' responses to section $\mathrm{D}$ of the online questionnaire were scored in such a way that when a respondent chose an "always" option, s/he was allotted a score of 4 , for a "sometimes" option, a score of 3 was allotted and when a "rarely" option was chosen, a score of 2 was allotted. Also, when a "Never" option was chosen, s/he was allotted a score of 1 . The resulting scores were aggregated and was made to constitute a measure of emotional intelligence possessed by each of the respondents. This measure was subjected to linear regression analysis using the communication effectiveness as the dependent (predicted) variable while emotional intelligence was used as the influencing (predictor) variable. The result of the model obtained was summarized in Table 2 along with the ANOVA test of its significance. 
Table 2: Influence of Emotional Intelligence on online communication effectiveness experienced by OAU students.

\begin{tabular}{cccccc}
\hline \multicolumn{3}{c}{ Model Summary } & \multicolumn{3}{c}{ ANOVA $^{\mathrm{b}}$} \\
\hline Model & $\mathrm{R}$ & R Square & Adjusted R & $\mathrm{F}$ & Sig \\
& & & Square & & \\
& & & 0.544 & 118.987 & $.000^{\mathrm{a}}$ \\
\hline
\end{tabular}

a. Predictors: (Constant), EI

b. Dependent Variable: CommEff

Table 2 presents the test of influence of emotional intelligence on online counselling communication effectiveness among OAU students. The table also shows that the R-square value obtained in the test was 0.548 and the adjusted R-square value was 0.544 . This may be interpreted to mean that emotional intelligence can explain a maximum value of $54.8 \%$ of the variance observed in the online counselling communication effectiveness experience by OAU students in the course of online counselling and a realistic value of only 54.4\%. The F-value obtained in the test of significance of the model was 118.987 at p-value of 0.000 . Since the p-value is less than 0.05 , it can be concluded that the model is significant. This implies that emotional intelligence has a significant influence on the online counselling communication effectiveness experience by OAU during of online counselling. The table of coefficient is presented in Table 3.

Table 3: Coefficient of the strength of influence of emotional intelligence on online counselling communication effectiveness among OAU students

\begin{tabular}{|c|c|c|c|c|c|c|}
\hline \multirow[t]{2}{*}{ Model } & & \multicolumn{2}{|c|}{ Unstandardized Coefficients } & Standardized & \multirow[t]{2}{*}{$\mathrm{T}$} & \multirow[t]{2}{*}{ Sig. } \\
\hline & & B & Std. Error & Beta & & \\
\hline \multirow{2}{*}{1} & (Constant) & 13.382 & 3.216 & & 4.161 & .000 \\
\hline & EI & .790 & .072 & .741 & 10.908 & .000 \\
\hline
\end{tabular}

a. Dependent Variable: CommEff

Table 3 shows the strength of influence of emotional intelligence on online counselling communication effectiveness among OAU students. It also shows that emotional intelligence wielded a strong influence on online counselling communication effectiveness among OAU 
students as B-value obtained is very high (0.790) with a t-value of 10.908 which is significant at 0.05 level of significance (significance value was less than 0.05 ).

Research Question \#3: What is the influence of the student-client social networking skills on the effectiveness of online counselling communication?

To answer research question 3, the student-clients' scores on social networking skill was obtained by scoring the responses provided by the research participants to the section $\mathrm{B}$ of the online questionnaire in such a way that when a respondent chose an "expert" option, s/he was allotted a score of 5, for a "good" option, a score of 4 was allotted and when a "fair" option was chosen, a score of 3 was allotted. Also, when a "Novice" option was chosen a score of 2 was allotted and when the respondent chose a "None" option, s/he was allotted a score of 1 . The resulting scores were aggregated and was made to constitute a measure of social networking skill demonstrated by each of the respondents. This measure was subjected to linear regression analysis using the communication effectiveness as the dependent (predicted) variable while social networking skill was used as the influencing (predictor) variable. The result of the model obtained was summarized in Table 4 along with the ANOVA test of its significance.

Table 4: Influence of Social networking skills on online communication effectiveness experienced by OAU students.

\begin{tabular}{cccccc}
\hline \multicolumn{3}{c}{ Model Summary } & \multicolumn{3}{c}{ ANOVA $^{\mathrm{b}}$} \\
\hline Model & $\mathrm{R}$ & R Square & Adjusted R & $\mathrm{F}$ & Sig \\
& & & Square & & \\
1 & $0.185^{\mathrm{a}}$ & 0.034 & 0.024 & 3.457 & $.066^{\mathrm{a}}$ \\
\hline
\end{tabular}

\footnotetext{
a. Predictors: (Constant), SNS

b. Dependent Variable: CommEff
}

Table 4 presents the test of influence of social networking skills on online counselling communication effectiveness among OAU students. The table also shows that the R-square value obtained in the test was 0.034 and the adjusted R-square value was 0.024 . This may be interpreted to mean that social networking skills can explain only a maximum value of $3.4 \%$ of the variance observed in the online counselling communication effectiveness observable among OAU students and a realistic value of only $2.4 \%$. The F-value contained on the test of significance of the model was 3.457 at $p$-value of 0.066 . Since the p-value is greater than 0.05 , it can be concluded that the model is not significant. 
Research Question \#4: What interaction effect does emotional intelligence and social networking skill have on online counselling communication effectiveness among OAU students?

To answer this research question, the student-clients' scores on online counselling communication effectiveness were subjected to a test of between subject effects via two-way ANOVA. The result is presented in Table 5

Table 5: Tests of Between-Subjects Effects

\begin{tabular}{lccccc}
\hline Source & $\begin{array}{c}\text { Type III Sum of } \\
\text { Squares }\end{array}$ & df & Mean Square & F & Sig. \\
\hline Corrected Model & $4017.310^{\mathrm{a}}$ & 89 & 45.138 & 1.980 & .118 \\
Intercept & 132971.440 & 1 & 132971.440 & 5832.081 & .000 \\
SNS & 801.072 & 27 & 29.669 & 1.301 & .343 \\
EI & 1618.061 & 17 & 95.180 & 4.175 & .013 \\
SNS * EI & 560.303 & 45 & 12.451 & .546 & .918 \\
Error & 228.000 & 10 & 22.800 & & \\
Total & 235895.000 & 100 & & & \\
Corrected Total & 4245.310 & 99 & & & \\
\hline
\end{tabular}

a. $\quad$ R Squared $=.946($ Adjusted R Squared $=.468)$

Dependent Variable: CommEff

Table 5 presents the test of the interaction effect of social networking skills and emotional intelligence on the online counselling communication effectiveness. It can be seen from the table that the F-value obtained for the interaction was 0.546 at p-value of 0.918 . Since the p-value is in excess of 0.05 , the interaction effect cannot be said to be significant, that is, the interaction between social networking skills and emotional intelligence has no significant influence on the online counselling communication effectiveness. It can be observed that although the R-square value rose to 0.946 but the Adjusted R-square value was depressed to 0.468 . This can be interpreted to mean that although, the interaction can account for a maximum of $94.6 \%$ and a realistic value of $46.8 \%$ of the variance observed in the online counselling communication effectiveness among OAU students, this cannot be attributed directly to the interaction between the two variables. It may be due to sampling error or mere chance. 


\section{Discussion of Findings}

Research question one was posed to investigate the level of online counselling communication effectiveness among students of Obafemi Awolowo University, Ile-Ife. The result obtained shows that most of the respondents (78\%) experienced a high level of communication effectiveness during their online interaction with their counsellors while $19 \%$ experienced moderate level. Only a very small percentage (3\%) indicated that they experienced low level of online counselling communication effectiveness. This is consistent with the findings by Asamu (2014) and Shahram and Sepasi (2012) where the larger percent of their respondents in online interaction possessed high level of communication effectiveness. This is because online communication allows individuals to explore the meaning and essence of the message sent before giving response (Asamu, 2014; Shahram \& Sepasi, 2012).

Also, because one of the factors that enhance communication is emotional intelligence, we attempted in this study to investigate its influence on online counselling communication effectiveness as experienced by OAU students through research question 2. Result shows that emotional intelligence significantly influences communication effectiveness. Hazard (2000) and Jadhav and Gupta (2014) suggested that emotional intelligence may lead to improved online communication effectiveness. Similarly, Goleman (2002) suggested that been emotionally intelligent in online communication is to effectively understand and express oneself and to understand and relate well with others. Individuals with better emotional intelligence can better perceive emotions, use them in thought, understanding the meaning of thought, and then encode/decode them in a proper message. Jadhav and Gupta (2014) show that emotional intelligence serves as a common ground in understanding online and global communications and in initiating effective communication (Sinha and Sinha, 2007) especially in online platforms (Mayer et.al, 2004; Deeter-Schmelz and Sojka, 2003).

The second factor examined in this study is the influence of social networking skills on online communication effectiveness among OAU students in online counselling relationship. Result shows that social networking skills have no significant influence on communication effectiveness among OAU students in online counselling relationship. This is consistent with the findings of Ellison, Steinfield, and Lampe (2007). They concluded that though social networking skills may be used to strengthen relationships that already exist and can enhance the feelings of closeness to others, as far as communication effectiveness was concerned, there were no perceived benefits of social networking skills. They suggested that this might be due to participants in online interactions being submerged in the social networking world and not considering how these 
activities are impacting their communication skills and their lives in general. Also, Drussell (2012) indicated that despite online social networking skills been very popular among students and other young adults, especially those of higher institutions of learning, a significant influence of social networking and social networking skills on effectiveness of online communication have not been found. This is because social media is an outlet which allow users to communicate in a manner they consider fit for themselves, often using for example, grammatically incorrect words, and spellings and emoticons etc., which have now become "normal" mode of online communication (Witmer \& Katzman, 1997; Marvin, 1995). However, this hampers communication effectiveness in online interactions as the use of these signs and languages may not really convey the message to the receiver, and the receivers of the message sometimes may find it difficult to comprehend the meaning of the words as truly intended by the sender (Walther \& D'Addario, 2001). This may then have a negative influence on the effectiveness of communication in online counselling relationship (Veytia-Bucheli, Gómez-Galán \& Vergara, 2020).

We also tried to determine the interactive effect of emotional intelligence and social networking skill on online counselling communication effectiveness among OAU students. The study result shows that the interaction of social networking skills and emotional intelligence has no significant influence on online counselling communication effectiveness, possibly because social networking skills may emotionally inhibit online media participants from positively responding to the emotions shown by other parties involved in the communication process (Benson, Ploeg \& Brown, 2010) or because the use of social media among adolescents may not improve their ability to understand and share the feelings of others, thereby leading to ineffective communication (Merwe, 2013).

\section{Author Contribution}

- Eli Segbeyon Gabriel was responsible for writing the draft background section as well as the literature review for this study. He was also involved in facilitating communications with the students during the online counselling sessions.

- Olusegun Fatai Adebowale was the chief counsellor who related with the students on the online counselling platform in question during the study. He oversaw the collection of data from the students/clients during the online counselling interactions. He also was involved in facilitating communications with the students during the online counselling sessions. 
- Oluwaseun Solomon Omotehinse was responsible for the analysis and interpretation of the data. He also was involved in facilitating communications with the students during the online counselling sessions.

\section{References}

Adebowale, O. F. (2010). Prospects and challenges of online Guidance and Counselling services at the Obafemi Awolowo University (Unpublished Masters' degree project). Obafemi Awolowo University. Ile-Ife. Nigeria.

Asamu, F. (2014). The Impact of Communication on Workers' Performance in Selected Organisations in Lagos State, Nigeria. IOSR Journal of Humanities and Social Science (IOSR-JHSS) Volume 19, Issue 8, PP 75-82.

Benson, G., Ploeg, J., \& Brown, B. (2010). A cross-sectional study of emotional intelligence in baccalaureate nursing students. Nurse Education Today, 30(1): 49- 53.

Cheney, G. (2011). Organizational communication in an age of globalization: Issues, reflections, practices. Long Grove, IL: Waveland Press.

Coleman, R. (2005). The moral media: How journalists reason about ethics. Mahwah, NJ: Lawrence Erlbaum.

Creed, C., \& Beale, R. (2006). Multiple and extended interactions with affective embodied agents. In C. Peter, R. Beale, E. Crane, L. Axelrod \& G. Blyth (Eds.), Emotion in HCI: Joint proceedings of the 2005, 2006 and 2007 Intl. Workshops, 123-136. Stuttgart: Fraunhofer IRB Verlag.

Davies, T. (2008). Youth work and social networking: Interim report. Leicester: National Youth Agency.

Deeter-Schmelz, D., \& Sojka, J. (2003). Developing effective salespeople: Exploring the link between emotional intelligence and sales performance. International Journal of Organizational Analysis, 11: 211-220.

Drussell, J. (2012). Social Networking and Interpersonal Communication and Conflict Resolution Skills among College Freshmen. Retrieved from Sophia, the St. Catherine University repository website: $h$ ttps://sophia.stkate.edu/msw_papers/21 
Ellison, N., Lampe, C., \& Steinfield, C. (2007). The Benefits of Facebook "Friends:" Social Capital and College Students' Use of Online Social Network Sites. Journal of ComputerMediated-Communication, 13, 210-230.

Francis, I., \& Chyke, G. (2016). Effective Communication As A Tool For Efficiency And Sustainability In Modern Organizations. International Journal of Innovative Development and Policy Studies, 4(3), 1-6.

Goleman, D. (2002). Primal leadership: Realizing the power of emotional intelligence. Boston, MA: Harvard Business School Publishing.

Goleman, D. (2004). Emotional Intelligence: Why it can matter more than IQ and Working with Emotional Intelligence. London, UK: Bloomsbury Publishing.

Gupta, S. (2017). Emotional Intelligence and Work Life Balance of Employees in the Information Technology Industry. Arabian Journal of Business and Management Review. Volume 6 (Issue 3) 1000201. ISSN: 2223-5833 AJBMR.

Hazard, N. (2000). The spirit of mentoring. Reflections on Nursing Leadership 26, 18-22.

Jadhav, T., \& Gupta, S. K. (2014). Global Communication Skills and Its Relationship with Emotional Intelligence. American Journal of Management vol. 14(4) 2014.

Keyton, J. (2011). Communication and organizational culture: A key to understanding work experience. Thousand Oaks, CA: Sage.

Marvin, L. E. (1995). Spoof, spam, lurk and lag: The aesthetics of text-based virtual realities. Journal of Computer-Mediated Communication, 1(2). http://207.201.161.120/jcmc/vol1/issue2/marvin.html

Mayer, J. D., Salovey, P. \& Caruso, D. R. (2004). TARGET ARTICLES: "Emotional Intelligence: Theory, Findings, and Implications.” Psychological Inquiry, 15(3), 197-215. doi:10.1207/s15327965pli1503_02. An International Journal for the Advancement of Psychological Theory

Shahram, M. \& Sepasi, H. (2012). Relationship between Communication Skills and Effectiveness. International Journal of Basic Sciences \& Applied Research. Vol., 1 (4), 101-106.

Merwe, P. (2013). Adolescent Violence: The risks and benefits of electronic media technology. Procedia Social Behavioural Science, 82:87- 93. 
Sinha, S. and Sinha, D. (2007). Emotional intelligence and effective communication. In A. Kaul \& S. Gupta (Eds.) Management Communication: Trends \& Strategies (pp. 450-460). Tata McGraw-Hill.

Tourish, D. (2010). Auditing organizational communication: A handbook of research, theory, and practice. New York, NY: Routledge.

Veytia-Bucheli, M. G., Gómez-Galán, J., \& Vergara, D. (2020). Presence of New Forms of Intercultural Communication in Higher Education: Emojis and Social Interactions through WhatsApp among Graduate Students. Education Sciences, 10(11), 295. doi:10.3390/educsci10110295

Walther, J. B., \& D'Addario, K. P. (2001). The Impacts of Emoticons on Message Interpretation in Computer-Mediated Communication. Social Science Computer Review, 19(3), 324-347. doi:10.1177/089443930101900307

Witmer, D., \& Katzman, S. (1997). On-line smiles: Does gender make a difference in the use of graphic accents? Journal of Computer-Mediated Communication, 2(4). http://www.ascusc.org/jcmc/vol2/issue4/witmer1.html 